Western University Scholarship@Western

1970

\title{
Monopoly and the Theory of International Trade
}

James R. Melvin

Robert W. Warne

Follow this and additional works at: https://ir.lib.uwo.ca/economicsresrpt

Part of the Economics Commons

Citation of this paper:

Melvin, James R., Robert W. Warne. "Monopoly and the Theory of International Trade." Department of Economics Research Reports, 7032. London, ON: Department of Economics, University of Western Ontario (1970). 
RESEARCH REPORT 7032

MONOPOLY AND THE THEORY

OF INTERNATIONAI TRADE

by

J. R. Me1vin

and

R. W. Warne

October, 1970 
MONOPOLY AND THE THEORY OF INTERNATIONAL TRADE

I Introduction

The pure theory of international trade concerns itself almost entirely with the case where all industries are perfectly competitive. ${ }^{1}$ While monopoly and other forms of imperfect competition are certainly a fact of life, the question of how these alternative market forms might be expected to alter the conclusions of the traditional theory has received surprisingly little attention. The purpose of this paper is to initiate such an investigation by considering, in the context of the two-good, two-factor, two-country model, the implications of either or both of the industries being monopolies.

Although our ultimate concern is with the question of the effects of monopoly on international trade, it will be necessary first of all to discuss the characteristics of the monopoly case for the autarky situation. This will be done in Section II. In Section III the question of the gains from trade will be discussed for the case in which both industries are monopolies, and in Section IV the factor price equalization theorem and the StolperSamuelson Theorem will be considered under the same assumptions. Section $\mathrm{V}$ will be concerned with the case where only one of the two industries is a monopoly, and Section VI will present a summary and some concluding remarks.

II The Autarky Model

Except for our assumption that both industries are monopolies rather

${ }^{1}$ Some attempts have been made to introduce the assumption of imperfect competition into the trade model. For a review of this literature see Richard E. Caves, Trade and Economic Structure (Cambridge, Mass.: Harvard University Press, 1963), pp. 174-89. Almost all of the discussion has been within a partial equilibrium framework. 
than being perfectly competitive, the assumptions of our model are the usual ones. We assume two countries, $\mathrm{H}$ and $\mathrm{F}$, producing two goods, $\mathrm{X}$ and $\mathrm{Y}$, using two homogeneous factors, labor ( $\mathrm{L}$ ) and capital (K) which are in fixed supply. The production functions are homogeneous of the first degree and are the same between countries but differ between goods. Consumers in both countries are assumed to have identical tastes which can be represented by homogeneous utility functions. Impediments to trade, such as transport costs and tariffs, are assumed to be absent. Finally, we confine our attention to the factor-endowment explanation of trade and assume that the overa11 capita1-1abor ratios for the two countries differ, and that there are no factor intensity reversals in the relevant range.

Because of our monopoly assumption our model differs from the traditional one in a number of respects. First, although we are assuming linear homogeneity, the sum of the returns of capital and labor do not equal the value of output. In monopoly the factors are paid their marginal revenue product rather than their marginal value product, and the excess of revenue over factor costs is profits. The point here is that while linear homogeneity is usually associated with perfect competition there is no conflict between our assumptions of monopoly and linear homogeneity of the production functions. Another difference between the monopoly case and perfect competition is that while in perfect competition we must have a large number of firms, and thus implicitly some upper limit on the size of firms, in monopoly we must have a situation in which there is no freedom of entry. We could, for example, assume that all production is under government franchise, or that patent rights prevent entry by would-be competitors.

The most fundamental difference, however, is that while in perfect competition aggregate demand and supply are independent and jointly determine 
prices and outputs, in monopoly we do not have this dichotomy. While consumers make their decisions independent of the production side, producers need information about demand in order to make any decision on output and price. In perfect competition the profit maximization condition is that (1) $\quad \mathrm{MC}=\mathrm{P}$,

while for a monopoly we have that

$$
\mathrm{MC}=\mathrm{MR}=\mathrm{P}\left[1-\frac{1}{\epsilon}\right],
$$

where $M C, M R, P$ and $\epsilon$ are, respectively, marginal cost, marginal revenue, price and the absolute value of the price elasticity of demand. This dependence of quantity produced on demand raises the question of the conditions under which an equilibrium can be assumed to exist; a question which will occupy our attention for the remainder of this section.

To consider the case of a two-industry country where both industries are monopolies, let us begin with the perfectly competitive case and see what happens when both industries become monopolies. In perfect competition all possible efficient production points describe the Edgeworth Box efficiency locus, and demand conditions will pick some particular point on that curve as the equilibrium position. In the output space this equilibrium is represented as the tangency between the production possibility curve and a community indifference curve, the slope at this common tangency being the equilibrium price ratio. Now suppose both firms become monopolies. Two changes will simultaneously take place. At the prevailing commodity prices the monopolists will tend to reduce output, while at the same time the lower costs due to the fact that factors are being paid less will tend to increase output. The interaction of these two forces will determine the position of the new equilibrium if such an equilibrium exists. Before presenting the 
rigorous demonstration of the conditions for the existence of such an equilibrium, a few observations can be made. First, under the assumption that factor returns will be the same in the two industries, it is clear that any equilibrium will be on the efficiency locus, i.e., on the production possibility curve. $^{2}$ Second, we will not, in general, expect the autarky equilibrium point to be the same under monopoly as it was in perfect competition, $^{3}$ and third, the slope of the production possibility curve will not, in general, be equal to the ratio of commodity prices. These last two points can be seen as follows. From equation (1) for the two industries in perfect competition we have

$$
\frac{M C_{x}}{M C_{y}}=\frac{P}{P_{y}},
$$

that is, the slope of the transformation curve (the ratio of marginal costs) is equal to the output price ratio. For monopoly we have, from equation (2), that

$$
\text { (4) } \quad \frac{M C_{x}}{M C_{y}}=\frac{M R_{x}}{M R_{y}}=\frac{P_{x}\left(1-1 / \epsilon_{x}\right)}{P_{y}\left(1-1 / \epsilon_{y}\right)}
$$

It is clear that only if the price elasticities of demand for $X$ and $Y$ are equal will monopoly give rise to the same production position and will the ratio of marginal costs equal the ratio of commodity prices. It is also clear from (4) that there are restrictions on the values that the elasticities can take in equilibrium. Neither elasticity can be less than unity, for

2 We are assuming that, even though there are only two buyers, the monopolists buy factors in perfectly competitive markets, i.e., the monopolists are not monopsonists.

3 Note that if the two equilibrium positions are identical, the only affect of monopoly is to redistribute income from factors to the monopolists. Because of our demand assumption this would not affect the final equilibrium. 
example, the other being greater than unity, for this would require that the ratio of marginal costs be negative. This is as we would expect, of course, for we know that a monopolist will never produce where the price elasticity is less than unity. We can already conclude, then, that an equilibrium will exist only if there is some range of outputs such that both demand elasticities are greater than unity.

Equation (4) can alternatively be written

$$
\frac{P_{x}}{P_{y}}=\frac{M C_{x}\left(1-1 / \epsilon_{y}\right)}{M C_{y}\left(1-1 / \epsilon_{x}\right)} \text {. }
$$

This formulation makes clear the reason that we must be concerned with the conditions under which an equilibrium will exist. From the demand side we know that any price ratio we choose will uniquely determine the ratio in which commodities are consumed and the two demand elasticities. Production of the commodities in this ratio implies a unique ratio of marginal costs, and then from equation (5) a unique price ratio for the equilibrium of producers is implied. The question is whether or not this latter price ratio can ever be equal to the price ratio which we initially imposed on consumers. 4 Before treating the general problem we will consider the special case where the utility functions exhibit constant elasticity of substitution and is of the form

$$
U=\left[a x^{-\beta}+b Y^{-\beta}\right]^{-1 / \beta} \text {, }
$$

where $-1<\beta<\infty, \beta \neq 0$, and where $\sigma$, the elasticity of substitution, is $\sigma=1 /(1+\beta)$. For this utility function the demand functions can be shown to be: ${ }^{5}$

\footnotetext{
${ }^{4}$ Mathematically, we want to know whether equation (5) has a fixed point. ${ }^{5}$ The derivation is given in Appendix A.
} 
(7)

$$
Y=\frac{M}{P_{y}\left[1+(a / b)^{1 /(\beta+1)}\left(P_{y} / P_{x}\right)^{-\beta /(\beta+1)}\right]}
$$

and

$$
X=\frac{M}{\left.P_{x}[1+b / a)^{1 /(\beta+1)}\left(P_{x} / P_{y}\right)^{-\beta /(\beta+1)}\right]} \text {, }
$$

and the corresponding demand elasticities are

$$
\epsilon_{y}=\frac{1+(a / b)^{1 /(\beta+1)}\left(P_{y} / P_{x}\right)^{-\beta /(\beta+1)} \frac{1}{(\beta+1)}}{1+(a / b)^{1 /(\beta+1)}\left(P_{y} / P_{x}\right)^{-\beta /(\beta+1)}}
$$

and

$$
\epsilon_{x}=\frac{1+(b / a)^{1 /(\beta+1)}\left(P_{x} / P_{y}\right)^{-\beta /(\beta+1)} \frac{1}{(\beta+1)}}{1+(b / a)^{1 /(\beta+1)}\left(P_{x} / P_{y}\right)^{-\beta /(\beta+1)}} .
$$

Since the numerators and denominators of (9) and (10) differ only by the expression $1 /(\beta+1)$, it is clear that whether the elasticity is greater than or less than unity depends solely on the value of $\beta$. The correspondence among $\beta$, the elasticities, and $\sigma$ is shown in the following table.

\begin{tabular}{ccc}
$\beta$ & $\epsilon_{\mathrm{x}}, \epsilon_{\mathrm{y}}$ & $\sigma$ \\
\hline$>0$ & $<1$ & $<1$ \\
$=0$ & $=1$ & $=1$ \\
$<0$ & $>1$ & $>1$
\end{tabular}

Observe that both elasticities are either greater than one, less than one, or equal to one. Thus to ensure that demand for both goods is elastic it is sufficient to assume that the elasticity of substitution is greater than unity. As we observed earlier, a necessary condition for the existence of an equilibrium implying positive output is that both elasticities be greater than unity. 
We can thus confine our attention hereafter to the case where $\beta<0 .{ }^{6}$ It is of interest to observe that since equations (9) and (10) are functions of price ratios only, the elasticities of demand are constant along any rate from the origin.

We now want to establish the existence and uniqueness of an equilibrium for our model. Observe that in equation (5), $\epsilon_{y}, \epsilon_{x}$, and $\mathrm{MC}_{\mathrm{x}} / \mathrm{MC}_{\mathrm{y}}$ are all functions of $\mathrm{P}_{\mathrm{x}} / \mathrm{P}_{\mathrm{y}}$ only. Equation (5) can thus be written as

$$
\text { (5') } \quad P=F(P) \text {, }
$$

where $\mathrm{P}=\mathrm{P}_{\mathrm{X}} / \mathrm{P}_{\mathrm{y}}$. The question of existence is thus a question of whether F has a fixed point. We will show that as we move along the transformation curve $F$ varies monotonically from 0 to $\infty$ as $P$ varies monotonically from

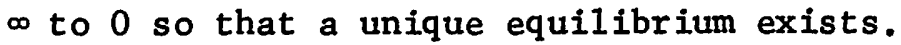

We will define the ratio of quantities produced along the transformation curve as $x=X / Y$. It is also useful to distinguish between $P_{c}$, the price ratio which would imply equilibrium for consumers at any $x$ (i.e., the slope of the community indifference curve at any $x)$, and $P_{p}$, the equilibrium price ratio for producers at any $x$ (i.e., the price ratio which would imply production of $\mathrm{X}$ and $\mathrm{Y}$ in the ratio $\mathrm{X}$ ). We will proceed to our theorem by establishing a number of lemmas.

Lemma 1: $P_{c}$ is a monotonic decreasing function of $x$. Furthermore $\lim _{x \rightarrow 0} P_{c}=\infty$

and

${ }^{6}$ Separating the cases of elastic demand and inelastic demand we have the Cobb-Douglas utility function where both the elasticity of substitution and the elasticity of demand are unity. 
$\lim _{x \rightarrow \infty} P_{c}=0$

Proof: It is well known that for CES functions the indifference curves touch the axes at points of tangency for the case where $-1<\beta<0 .^{7}$ Thus as $x \rightarrow 0, p \rightarrow \infty$ and as $x \rightarrow \infty, p-0$. Because of continuity and homogeneity $P_{c}$ increases monotonically from 0 to $\infty$ and $x$ decreases monotonically from $\infty$ to 0 .

Lemma 2: a) $\epsilon_{\mathrm{x}}$ is a monotonic decreasing function of $\mathrm{x}$ and $\epsilon_{\mathrm{y}}$ is a monotonic increasing function of $x$. Furthermore:

$$
\text { b) } \lim _{x \rightarrow 0} \epsilon_{x}=\sigma, \quad \lim _{x \rightarrow \infty} \epsilon_{x}=1
$$

and

$$
\lim _{x \rightarrow 0} \epsilon_{y}=1, \quad \lim _{x \rightarrow \infty} \epsilon_{y}=\sigma
$$

Proof: From equation (10) the second term of the numerator is larger than the second term of the denominator by the factor $\sigma>1$. Then since $-\beta /(\beta+1)>0$, any increase in $P_{c}$ will increase the numerator more than the denominator, so that $\epsilon_{\mathrm{x}}$ is a monotonic increasing function of $P_{c}$. Similarly, $\epsilon_{y}$ is a monotonic increasing function of $1 / P_{c}$, or a monotonic decreasing function of $P_{c}$. Then from Lemma 1 , Lemma $2(a)$ is established. Equation (10) can be written

$$
\text { (10') } \epsilon_{x}=\frac{1+\theta \sigma}{1+\theta}
$$

where $\theta=f(P)$. Since $-\beta /(1+\beta)>0$, we have that $\lim \theta=\infty$. From Lemma 1 we have that $\lim P=\infty$, so that $P \rightarrow \infty$

$$
x \rightarrow 0
$$

7 For example, see John S. Chipman, "A Survey of the Theory of Internationa1 Trade: Part 3, The Modern Theory," Econometrica, 34 (January, 1966), pp. 57-9. 
(11) $\lim _{x \rightarrow 0} \theta=\infty$.

From $\left(10^{\prime}\right)$ we can write

$$
\lim _{0 \rightarrow \infty} \epsilon_{x}=\lim _{0 \rightarrow \infty} \frac{1+\theta \sigma}{1+\theta}=\lim _{\theta \rightarrow \infty} \frac{1 / \theta+\sigma}{1 / \theta+1}=\sigma
$$

Then from (11) we have

(12) $\lim _{x \rightarrow 0} \epsilon_{x}=\sigma$,

which establishes the first part of Lemma 2(b). The remaining three expressions in Lemma $2(\mathrm{~b})$ can be proved in the same way.

Lemma 3: a) $P_{p}$ is a monotonic increasing function of $x$, and furthermore

b) $\lim _{x \rightarrow 0} P_{p}=0 \quad$ and $\quad \lim _{x \rightarrow \infty} P_{p}=\infty$

Proof: We have established that

$$
P_{p}=\frac{M C_{x}\left(1-1 / \epsilon_{y}\right)}{M C_{y}\left(1-1 / \epsilon_{x}\right)}
$$

From Lemma 2 it is easily shown that

$$
\lim _{x \rightarrow 0} \frac{\left(1-1 / \epsilon_{y}\right)}{\left(1-1 / \epsilon_{x}\right)}=0
$$

and

(14) $\lim _{x \rightarrow \infty} \frac{\left(1-1 / \epsilon_{y}\right)}{\left(1-1 / \epsilon_{x}\right)}=\infty$

It is also clear that $\frac{\left(1-1 / \epsilon_{y}\right)}{\left(1-1 / \epsilon_{x}\right)}$ is a monotonic increasing function of $x$. $M C_{x} / M C_{y}$ is the slope of the transformation curve, and under the assumption that the production functions are homogeneous of the first degree, will be an increasing function of $x$. Then since the limit of a product is equal 
to the product of the limits Lemma 3 is established.

From Lemma 1 and Lemma 3 the following theorem is immediate.

Theorem 1: For a CES utility function, and assuming that $-1<\beta<0$, there exists a unique equilibrium price ratio satisfying equation (5).

While a CES utility function with $-1<\beta<0$ is certainly sufficient for the existence of a unique equilibrium, it is by no means necessary. This can perhaps best be illustrated by referring to Figure 1 where we have plotted $P_{c}$ and $P_{p}$ as functions of $x$ in accordance with Lemmas 1 and 3 . The equilibrium price is $\mathrm{P*}$. It is clear from the figure that in general it will not be necessary for both $P_{p}$ and $P_{c}$ to range from 0 to $\infty$. For example, as long as $P_{p}$ is as shown, then any homogeneous concave utility function (which guarantees that $P_{c}$ will not be an increasing function of $x$ ) will result in a unique equilibrium. And note that since $P_{c}$ will be defined for all $x, P_{p}$ need not be. Thus all that is necessary is that there be a range of $\mathrm{x}$ for which both elasticities are greater than unity, with one elasticity being unity or less outside this range (to ensure that $P_{p}$ varies from 0 to infinity). Alternatively if $P_{c}$ is as shown, then as long as for some range of $x$ both price elasticities are greater than unity, and as long as $\epsilon_{\mathrm{x}}$ is an increasing and $\epsilon_{y}$ a decreasing function of $x$, (which guarantees that $P_{p}$ will be an increasing function of $x$ ) then a unique equilibrium will exist. Note that $P_{c}$ will be as shown in Figure 1 as 1 ong as at all positive, finite consumer price ratios some of both goods are consumed.

We can thus state two corollaries for Theorem 1

Corollary 1: If a) both goods are consumed at all price ratios,

b) there exists a range of $\mathrm{x}$ for which both elasticities are greater than unity, and 
$-11-$

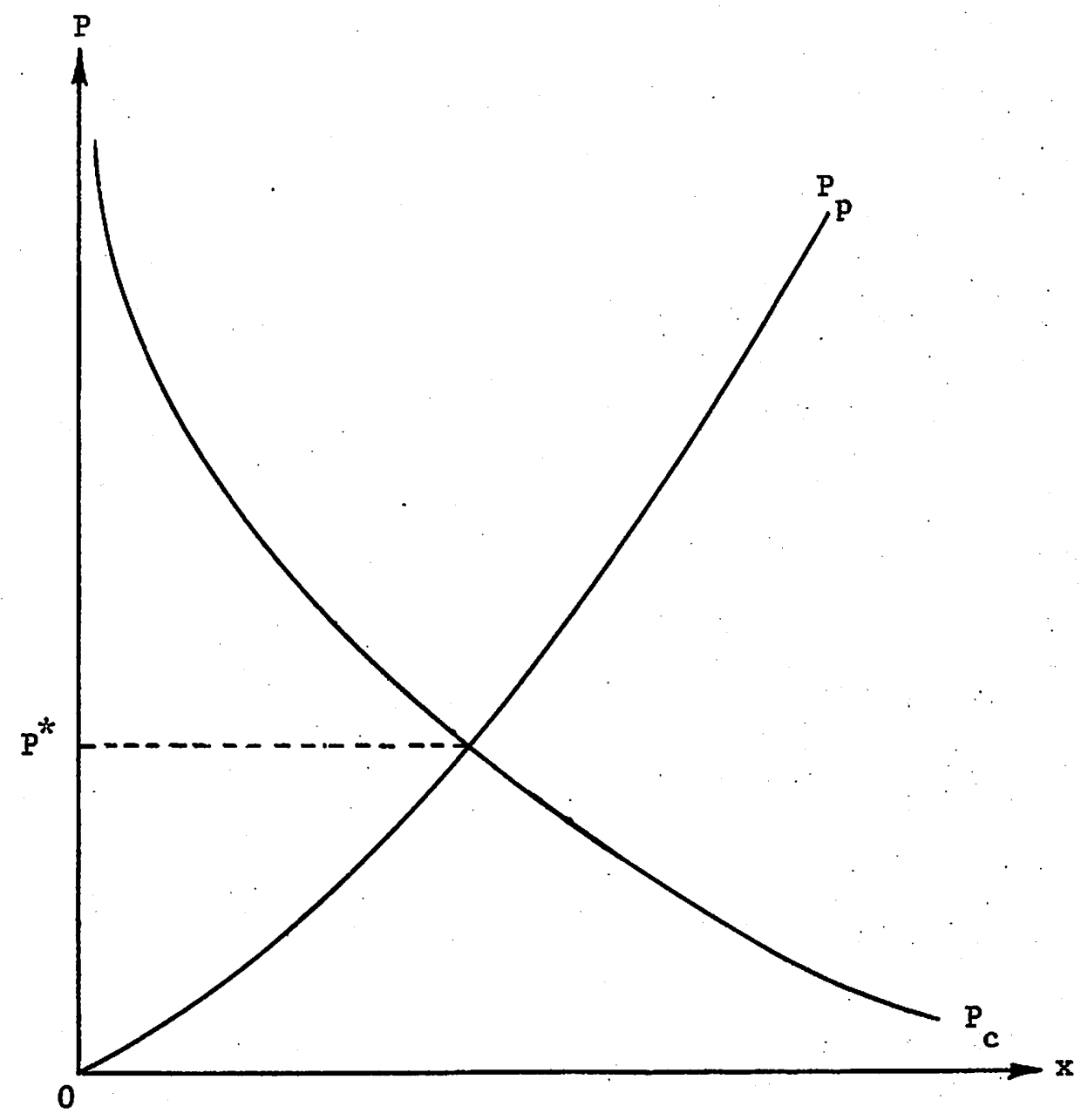

Figure 1 
e) $\epsilon_{x}$ is an increasing and $\epsilon_{y}$ a decreasing function of $x$, then there will exist a unique equilibrium price ratio.

Corollary 2: If a) the utility function is homogeneous and concave,

b) there exists a range of $\mathrm{x}$ for which both elasticities are greater than unity, and such that outside this range one elasticity is less than or equal to unity, and

c) $\epsilon_{x}$ is an increasing and $\epsilon_{y}$ a decreasing function of $x$, then there will exist a unique equilibrium price ratio.

We now want to establish where on the transformation curve the equi1ibrium will 1ie. As a point of reference suppose we consider the case where $\epsilon_{\mathrm{x}}=\epsilon_{\mathrm{y}}$. As we pointed out earlier, this is a necessary and sufficient condition for the output price ratio $\left(P_{p}\right)$ to be equal to $\mathrm{MC}_{\mathrm{x}} / \mathrm{MC} \mathrm{y}_{\mathrm{y}}$, the slope of the transformation curve. Thus from (9) and (10) we would have

$$
\frac{1+\theta \sigma}{1+\theta}=\frac{1+\phi \sigma}{1+\phi}
$$

where $\theta=(b / a)^{1 /(\beta+1)}\left(P_{c}\right)^{-\beta /(\beta+1)}, \phi=(a / b)^{1 /(\beta+1)}\left(1 / P_{c}\right)^{-\beta /(\beta+1)}$.

It is clear that with $\sigma \neq 1$ this equality can hold if and only if $\theta=\phi$.

Thus we have

$$
(b / a)^{1 /(\beta+1)}\left(P_{c}\right)^{-\beta /(\beta+1)}=(a / b)^{1 /(\beta+1)}\left(1 / P_{c}\right)^{-\beta /(\beta+1)} .
$$

Simplifying we obtain:

$$
b / a=\left(P_{c}\right)^{\beta}
$$

or

$$
\text { (15) } \quad P_{c}=(b / a)^{1 / \beta} \text {. }
$$

Thus (15) is a necessary and sufficient condition for $\epsilon_{X}=\epsilon_{y^{*}}$ It can also be seen from equations (7) and (8) that $\theta=\phi$ implies that $Y / X=P_{c}$. 
In Figure 2 we have represented the ray along which the elasticities are equal as $0 x^{*}$. Equation (5) implies that at $S, P_{p}$ will be tangent to the transformation curve. Of course since the production functions and the utility function are independent there is no reason to expect that an indifference curve will be tangent to the transformation curve at $\mathrm{S}$, and indeed such a situation would represent just one of an infinity of possibilities. In Figure 2 the tangency of an indifference curve and the transformation curve is point $A$, the equilibrium point which would exist in a perfectly competitive model. Obviously only by pure chance will the monopoly situation give rise to the same equilibrium as the perfectly competitive system. Of course A could be on either side of $\mathrm{S}$.

As we move from $S$ along the transformation curve towards the $Y$ axis, $x$ decreases, which implies that $\epsilon_{x}$ becomes larger and $\epsilon_{y}$ becomes smaller. These, in turn, imply that $\left(1-1 / \epsilon_{y}\right) /\left(1-1 / \epsilon_{x}\right)$ becomes less than unity, so that, from (5), $\mathrm{MC}_{\mathrm{x}} / \mathrm{MC} \mathrm{y}_{\mathrm{p}}>\mathrm{P}_{\mathrm{p}}$. Thus at $\mathrm{S}, \mathrm{P}_{\mathrm{p}}>\mathrm{P}_{\mathrm{c}}$, and at $\mathrm{A}_{,} \mathrm{P}_{\mathrm{p}}<\mathrm{P}_{\mathrm{c}}$, so that the equilibrium, point $E$, must lie strictly between $S$ and $A$. Thus the equilibrium $\mathrm{x}$ will be bounded by the perfectly competitive $\mathrm{x}$ and $x^{*}=(a / b)^{1 / \beta}$. III Monopoly and the Gains from Trade

From Figure 2 it is clear that in autarky the highest community indifference curve is reached at the perfectly competitive equilibrium, point A, Monopoly which leads to an equilibrium at point E will result in consumption taking place on a lower indifference curve, and in this sense the monopoly situation is inferior to the perfectly competitive one.

If we assume that the country of Figure 2 is small relative to the rest of the world, and if the rest of the world is assumed to be perfectly 


$$
X
$$


competitive, then when trade is allowed, and if, because of competition from the rest of the world, the domestic industries are forced to behave as perfect competitors, the final equilibrium will be identical to the one which would have occurred if initially perfect competition had prevailed domestically. The gains from trade will be greater than in the perfectly competitive case, however, because there are now gains from two sources. As well as the usual gains from trade we also have the gain due to the removal of the distortion due to monopoly. In general we will not know which component of the total gain is larger, but there seems to be no reason why the gain due to the removal of the monopoly distortion could not be as large as the perfectly competitive gain from trade.

We now want to consider the two-country case where the industries of both countries are assumed to be monopolies. This raises a conceptual problem, however, for when trade is allowed there will be two firms producing each good rather than one, so we actually have a duopoly situation. In order to avoid the difficulties associated with duopoly we will assume that each firm acts as if it were a monopoly and treats its share of the world market as the total market for the commodity. Alternatively, we could assume that the two firms producing each of the two goods is owned and controlled by the same company, so that we would have two companies, each with a home firm and a foreign subsidiary. The analysis will be the same under either assumption.

Another point deserves brief comment, and that is the question of what elasticity is relevant when a firm is selling in both the domestic and foreign market. This question is easily solved by observing that both countries have been assumed to have the same homogeneous utility functions, 
so that when commodity prices are the same in the two countries, the demand elasticities will be the same as well. Recall that the elasticities are functions of the price ratio only. The elasticity relevant to a particular point on the transformation curve for either of the countries is the elasticity of demand associated with the consumption point for that country (or, alternatively, with the vector of world output) and not the elasticity associated with the individual country's production point. This can be seen by examining Figure 3, where the world production possi-

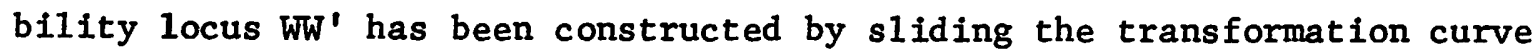
of country $F$ over that of country $H$. Associated with $T$, the point of tangency between the two production sets, we have the world output point $E_{W}$. To find the producer price ratio associated with $T$ we use the elasticity of demand associated with the indifference curve passing through $E_{w}$. Note that from equation (5) with equal elasticities for the two countries, equality of the ratios of marginal costs implies equality of producer price ratios. To put the matter another way, equality of the elasticities in the two countries implies that if producer price ratios are equal, then the two production surfaces will be tangent as in Figure 3 . In this sense the world production possibility curve depends on our demand assumptions. Of course in constructing the world transformation curve there will be regions where one or the other of the two countries specialize, so that there will not be tangency between the two production possibility curves in these regions. In this case, the relevant marginal-cost ratio will be the one prevailing in the country which is still producing both goods.

In Figure 3, the slope of the world transformation curve at any point 
$-17-$

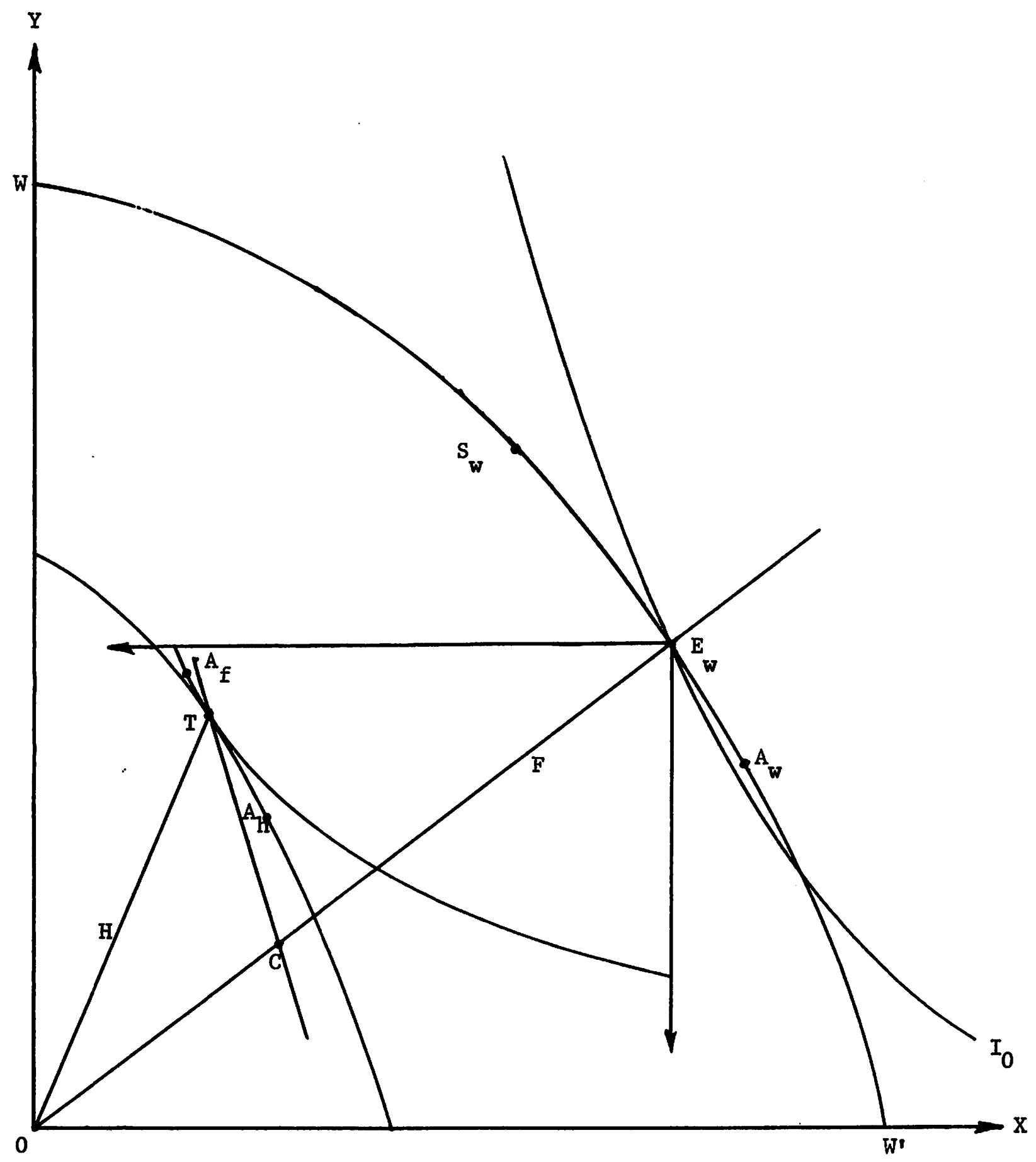

Figure 3 
such as $\mathrm{E}_{\mathrm{W}}$ is equal to the slope of the individual country transformation curves at $T$, the point which gave rise to $\mathrm{E}_{\mathrm{W}}$. Thus the proof of the existence of a world equilibrium can proceed in exactly the same way as the proof of the existence of an equilibrium for an individual country. Furthermore, there will be a point $S_{w}$ where, because the elasticities of demand for the two goods are equal, the world producer price ratio will be tangent to the world transformation curve, and there will be a point $A_{w}$ where an indifference curve is tangent to the world transformation curve. $A_{W}$ would be the world equilibrium point under perfect competition. The world equilibrium point will be somewhere between $S_{w}$ and $A_{w}$, and could, for example, be $E_{w}$. From Figure 3 it is clear that the world is on a lower indifference curve than it would be with perfect competition. 8

We want to examine the question of the gains from trade in the context of our monopoly model, but before doing so, it is of interest to point out that the Heckscher-Ohlin Theorem applies to the monopoly case. From Figure 3 it is clear that country $\mathrm{H}$ is relatively well endowed with the factor used intensively in the production of $Y$, while country $G$ is relatively well endowed with the factor used intensively in the production of $\mathrm{x}$. Because of our demand assumptions both countries will consume along the ray $\mathrm{OE}_{\mathrm{w}}$, and since $\mathrm{OT}$, the production ray for country $\mathrm{H}$, implies more $\mathrm{Y}$ and less $\mathrm{X}$ than $\mathrm{OE}_{\mathrm{W}}$, country $\mathrm{H}$ must be exporting $\mathrm{Y}$ and importing $\mathrm{X}$. Similarly country $\mathrm{F}$ is exporting $\mathrm{X}$ and importing $\mathrm{Y}$. And observe that this must always be true since at any common price ratio equilibrium prom duction in $\mathrm{H}$ implies a lower value for $\mathrm{x}$ than in $\mathrm{F}$, and since the proportion

8 There is, of course, the possibility that $A_{w}, E_{w}$ and $S_{w}$ will coincide so that the monopoly and the perfectly competitive equilibria would be the same. As in the case of a single country, such a case would represent just one of an infinity of possibilities. 
of the two goods in consumption is the same for the two countries, it must lie between the two production vectors.

We can now turn to the question of the gains from trade for the case where both industries are monopolies in both countries. There are two types of questions we want to consider. One is how trade in the monopoly case compares to trade in the perfectly competitive case, and the other is whether in the monopoly case trade is necessarily preferable to autarky. 9 We have already observed that $\mathrm{E}_{\mathrm{w}}$ is on a lower indifference curve than $A_{W}$, so that from the point of view of the world, perfect competition is preferable to the monopoly situation. This is not necessarily the case for the individual countries, however. In Figure 3, OC represents the consumption vector for country $\mathrm{H}$, and $\mathrm{E}_{\mathrm{W}} \mathrm{C}$ the consumption vector for country F. In Figure 3 it is clear that with perfect competition country $\mathrm{H}$ would be on a higher indifference curve than the one tangent at point $C$, and this would seem to be the normal situation. It is possible, however, that country $\mathrm{H}$ could be better off with monopoly. For example, TC, the monopoly equilibrium price line, could intersect the transformation curve for country $\mathrm{H}$ twice, and if the second intersection lies between $\mathrm{T}$ and $A_{h}$, then monopoly will result in a higher level of welfare for country $H$. Observe that since the elasticities of demand are equal to $\mathrm{s}_{\mathrm{w}}$, and since $\epsilon_{\mathrm{x}}$ decreases and $\epsilon_{\mathrm{y}}$ increases as $\mathrm{x}$ increases, at both $\mathrm{A}_{\mathrm{w}}$ and $\mathrm{E}_{\mathrm{w}}$ we have that $\epsilon_{y}>\epsilon_{x}$. Thus if Figure 3 can be regarded as the normal situation for country $\mathrm{H}$, the movement from perfect competition to monopoly can be presumed to be harmful to the country which has a comparative advantage in

9 Throughout our discussion of the gains from trade, we will assume that a movement to a higher indifference curve represents a gain in welfare. 
$-20-$

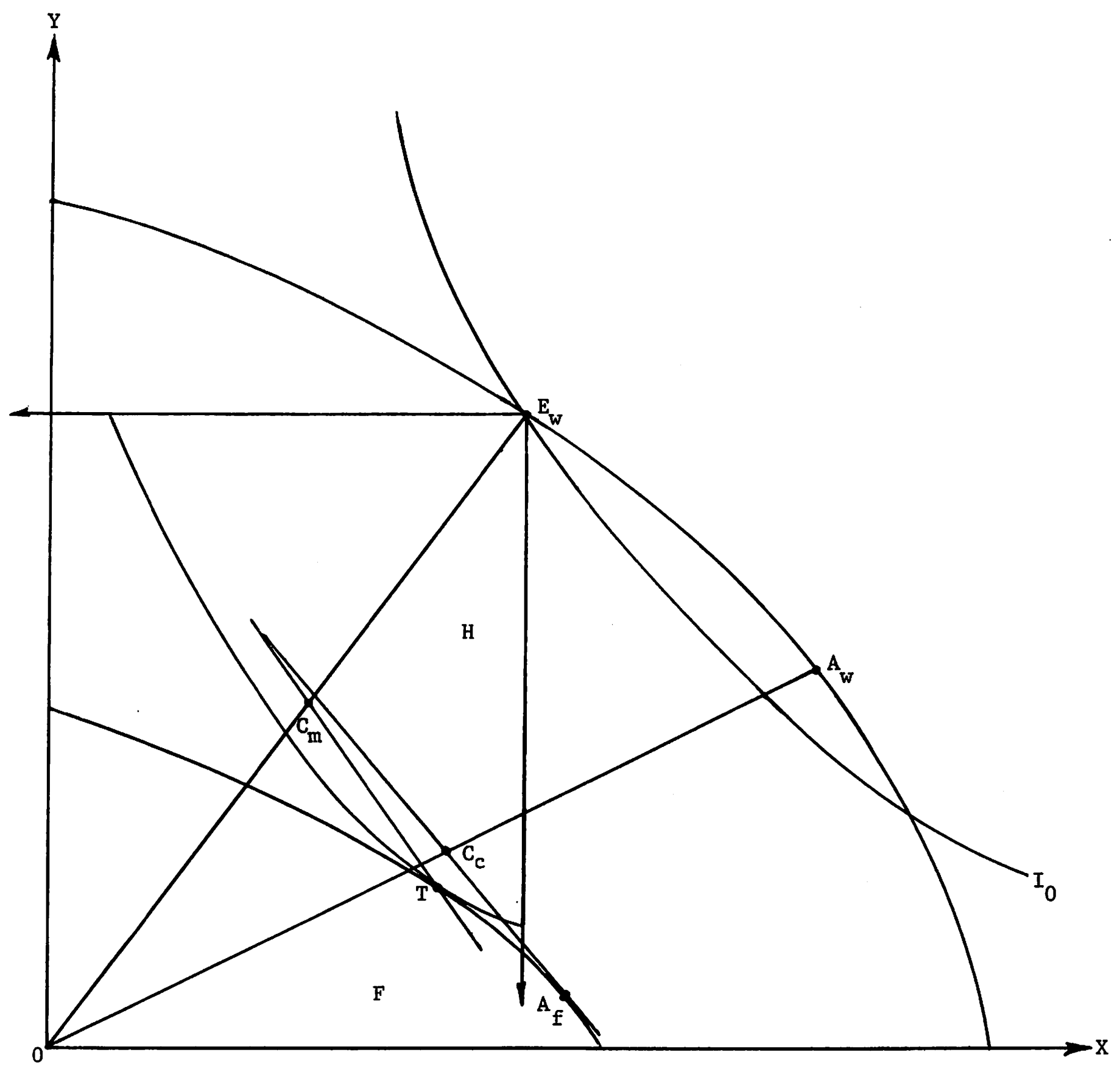

Figure 4 
the good with the higher elasticity of demand.

As Figure 3 is drawn country $F$ would be in a better position than with perfect competition. If $A_{f}$ represents the point on the transformation curve for country $\mathrm{F}$ at which the perfectly competitive price ratio line would be tangent, then this price line passes below $C$, i.e., between $\mathrm{E}_{\mathrm{W}}$ and $C$, so that the perfectly competitive equilibrium point, which will be on the ray $\mathrm{OA}_{\mathrm{W}}$, is inferior to the monopoly situation. This is by no means necessary as is shown in Figure 4 where, in order to allow an easy comparison of equilibrium consumption points, we have exchanged the positions of the two countries. $\quad c_{c}$ is the perfectly competitive consumption point for both countries while $\mathrm{C}_{\mathrm{m}}$ is the monopoly consumption position. Since the perfectly competitive price line, which passes through $C_{c}$ and $A_{f}$, passes above $C_{m}$, i.e., intersects $O_{w}$ between $C_{m}$ and $E_{w}$, it is clear that $\mathrm{C}_{c}$ is on a higher indifference curve than $\mathrm{C}_{\mathrm{m}}$, so that in this case the perfectly competitive equilibrium is superior to the monopoly equilibrium. Note that in Figure 4, country $\mathrm{H}$ is also made worse off by moving from perfect competition to monopoly. For country $H$ the perfectly competitive price line also passes above $C_{m}$, i.e., intersects $O E_{w}$ between 0 and $C_{m}$. Having compared the perfectly competitive trade situation with the monopoly trade situation we now turn to a comparison of the monopoly autarky situation and the monopoly trade situation. From Figure 3 and Figure 4, for country $H$ the consumption point with trade is in the interior of the production possibility set so that it is quite probable, although not certain, that trade will leave country $\mathrm{H}$ on a lower indifference curve than autarky. This is not certain because the autarky indifference curve intersects the production possibility curve so that there are points in the interior of the production set which are superior to the autarky 
consumption point. Country F will always be on a higher indifference curve with trade, for the indifference curve reached at point $\mathrm{C}$ in Figure 3 could not be reached in autarky. We can conclude then that if monopoly of the kind we have described exists, then with trade the country having a comparative advantage in the good having the lower price elasticity will gain from trade, while the country having a comparative advantage in the good having a higher price elasticity may very well lose from trade. This clearly represents a situation where a prohibitive tariff is justified for the losing country, although it may be possible for the country that gains to bribe the country that loses so that they both can gain. There is also the possibility that in the monopoly case the world as $a$ whole may be worse off with trade than with autarky. Although it is clear that the sum of the autarky production (and consumption) points for the two countries will be in the interior of the world production set, there are points in the interior of the production set which are sum perior to the world trade position, namely those points in Figure 4 which are both in the world production set and above the indifference curve passing through $E_{w^{-}}$If the vector sum of $E_{f}$ and $E_{h}$, the autarky equilibrium points, lies in this region, then trade will lead to a reduction in the welfare level of the world. 10

IV Factor Price Equalization and the Stolper-Samuels on Theorem

Two theorems which have received considerable attention within the framework of the Heckscher-Ohlin model are the factor price equalization

10 This situation contrasts with the case where there are increasing returns to scale. With increasing returns, although trade may move one country to an inferior position, the world will be better off, so that the gaining country could bribe the losing country to allow free trade to take place. See James R. Melvin, "Increasing Returns to Scale as a Determinant of Trade," Canadian Journal of Economics, II (August, 1969). 
theorem and the Stolper-Samuelson Theorem and it is of interest to see whether these theorems can be established in our present model. We have seen that the basic Heckscher-Ohlin conclusion, namely that a country will export the commodity which uses intensively the factor with which it is relatively we1l endowed, holds in the monopoly case as well as the perfectly competitive case while, in general, the gains from trade theorem does not. We want to establish whether, for these other two theorems, the assumption of perfect competition can be dispensed with.

The question of whether we should expect relative factor prices to be equalized can be solved quite easily. We first observe that from the production side, i.e., the listing of all possible output points and the conditions necessary to achieve these output levels, the monopoly model we have described does not in any way differ from the perfectly competitive model. As can be seen from Figure 3, the world production possibility curve is identical to that for perfect competition, and since the overall allocation of factors among the industries of the two countries is unique for any output configuration, it must be the same for monopoly as for perfect competition. Thus, for cases in which both countries are producing both goods, and excluding the possibility of factor intensity reversals, factor price equalization can be proved for the monopoly case exactly as it can for perfect competition. ${ }^{11}$

To be somewhat more formal we will consider the general proof of

${ }^{11}$ This contrasts with a statement made by H. Robert Heller, International Trade: Theory and Empirical Evidence (Englewood Cliffs: Prentice Hall, Inc., 1968), p. 98, In discussing factor price equalization he claims that "The assumption of perfect competition is a necessary one which cannot be relaxed." 
factor price equalization as presented by Chipman. ${ }^{12}$ It is assumed that there are $n$ commodities, produced in amounts $y_{i}, i=1, \ldots, n$, and $n$ factors which exist in fixed amounts $x_{1}, x_{2}, \ldots, x_{n}$. The production function can be written as

$$
y_{i}=f_{i}\left(x_{i 1}, x_{i 2}, \ldots, x_{i n}\right)
$$

The production function is assumed to be homogeneous of the first degree and concave. Factor prices, $w_{1}, \ldots, w_{n}$ are assumed by the monopolist to be given and beyond its control. We also assume that there is perfect mobility of factors among industries so that the return to a factor is the same in all industries. Now minimizing cost subject to the production function, the minimum cost function factors into

$$
c_{i}\left(y_{i}, w_{1}, \ldots, w_{n}\right)=y_{i} \cdot g_{i}\left(w_{1}, \ldots, w_{n}\right)
$$

where $g_{i}$ is homogeneous of the first degree and concave. Dividing both sides by $y_{i}$ we obtain the minimum unit cost as a function of factor prices only,

$$
c_{i}=g_{i}\left(w_{1}, \ldots, w_{n}\right)
$$

It is at this stage that our analysis must differ from Chipman's, for while Chipman is able to argue that per unit cost, which is equal to marginal cost will, under perfect competition, be equal to price as Iong as the good is produced, such an argument cannot be used in the monopoly case. Instead we can say that as long as the good is produced, and since marginal and average cost are equal, we have that $p_{i}=c_{i}\left(1-1 / \epsilon_{i}\right)$, or, that

12 John S. Chipman, "A Survey of the Theory of International Trade: Part 3, The Modern Theory," Econometrica, 34 (January, 1966), pp. 19-21. We consider only the case of an equal number of goods and factors. 
(19)

$$
c_{i}=p_{i} /\left(1-1 / \epsilon_{i}\right),
$$

where $p_{i}$ is the price of commodity $i$. If we define $p_{i}^{*}=p_{i} /\left(1-1 / \varepsilon_{i}\right)$ we can write $p_{i}^{*}=g_{i}\left(w_{1}, \ldots, w_{n}\right)$, or in vector notation,

$$
p^{*}=g(w) \text {, }
$$

where $p^{*}=\left(p_{i}^{*}, \ldots, p_{n}^{*}\right)$ and $w=\left(w_{1}, \ldots, w_{n}\right)$.

Now, if all $\mathrm{n}$ goods are produced in all countries, and are all traded, and if the function $g$ is globally invertible, we have

$$
w=g^{-1}\left(p^{*}\right) \text {, }
$$

so that in each country the $w$ vector is uniquely determined by $\mathrm{p}^{*}$. The $P_{i}$ are equal in all countries due to trade, and since utility functions are homogeneous and the same for all countries, and with the same prices, then the $\epsilon_{i}$ 's are the same for all countries as well. Thus $p^{*}$ will be identical among countries so that factor prices will be equalized.

There is, however, one basic difference between the monopoly case and the perfectly competitive case. While with perfect competition no explicit mention need be made of demand conditions, and there is certainly no need for them to be the same between countries, ${ }^{13}$ with monopoly a specific assumption about demand conditions must be included. This results from the fact that producers cannot make decisions on price and output without information about demand conditions.

One other factor which somewhat complicates the monopoly situation is the question of what happens to the monopoly profits, and whether these affect economic decisions. The simplest approach would seem to be to

${ }^{13}$ This is not to say that in the competitive case demand conditions are of no importance, for it will be demand conditions which determine whether or not all countries will produce all goods. Thus demand conditions will determine whether the assumption of incomplete specialization holds. 
assume that monopoly profits are distributed to individuals in a lump sum fashion so that marginal conditions will not be disturbed. However, since profits per unit of output will generally vary between industries, and since countries will tend to specialize when there is trade, profits per capita will be expected to be different among countries. The factor prices we have discussed to this point have not included profits, so that when profits are included the overall return to factors may differ among countries although the ratios of earned rewards will be the sane. This fact could have important implications if factor mobility is allowed and if factors move in response to total rewards. 14

We will now turn our attention to the Stolper-Samuelson Theorem which in its simplest form states that a tariff will benefit the scarce factor absolutely. In other words, a tariff will increase the return of the scarce factor relative to the price of both goods. ${ }^{15}$ The argument depends first on the premise that when a tariff is imposed, production will shift away from our export good, the good whose production used our abundant factor most intensively, and towards our import good, the good which used the scarce factor most intensively. This will increase the demand for, and therefore the price of, our scarce factor, and in both industries we will find that the scarce factor will be used less intensively than before. This in turn implies that the marginal physical product of the scarce factor will rise, and then since in perfect competition, factors are paid

${ }^{14}$ Although space does not permit a lengthy discussion of factor mom bility, it can easily be shown that the country specializing in the good having the lower elasticity of demand will have higher per capita profits. Thus, in Figure 3, if there is factor mobility, both capital and labor will tend to move from country $H$ to country $F$.

${ }^{15}$ As is well known, there are certain qualifications which must be made to this simple statement of the theorem, and these will apply to our discussion as well. We will not discuss these here since our concern is with the basic premise of the theorem. 
the value of their marginal product in both industries, the real return to the scarce factor will increase relative to both industries. We have

$$
\operatorname{MPP}_{s}=\frac{w_{s}}{P_{i}} \text {, }
$$

where $\mathrm{MPP}_{s}$ and $\mathrm{w}_{s}$ are, respectively, the marginal physical product and the return of the scarce factor, and where $P_{i}$ is the price of commodity $i$. Then since (22) is an equilibrium condition, if the left hand side increases so must the right hand side.

In our monopoly situation, however, we must replace equation (22) with the statement that factors are paid their marginal revenue product, so that we have

$$
\text { (23) } \quad \mathrm{MPP}_{s}=\mathrm{w}_{s} / \mathrm{MR}_{i} \text {. }
$$

Then since $\mathrm{MR}_{i}=\mathrm{MC}_{i}=\mathrm{P}_{i}\left(1-1 / \epsilon_{i}\right)$ we have

$$
\text { (24) } \quad \operatorname{MPP}_{s}\left(1-1 / \varepsilon_{i}\right)=\frac{w_{s}}{P_{i}} \text {. }
$$

As before, a tariff will increase $\mathrm{MPP}_{s}$, but now whether this will increase $w_{s} / P_{i}$ depends on what happens to $\varepsilon_{i}$, and as we have already observed, it will increase for one good and decrease for the other. In particular, referring again to the situation implicit in Figure 3, a tariff in $\mathrm{H}$ will reduce the production of $Y$ and increase the production of $X$ so that $\epsilon_{X}$ will fall and $\epsilon_{y}$ rise. Thus $\left(1-1 / \epsilon_{x}\right)$ will fall and $\left(1-1 / \epsilon_{y}\right)$ will rise and then while $w_{s} / P_{y}$ will clearly rise the change in $w_{s} / P_{x}$ is indeterminate. Thus the Stolper-Samuelson results cannot be proved in a monopoly situation.

V Monopoly in One Industry only

To this point we have concentrated our attention on the case where 
both industries in both countries are monopolies, and it is now quite a simple task to consider the special case where only one of the two industries is a monopoly in both countries. Assuming that it is the industry producing $\mathrm{X}$ which is monopolized in both countries, we have that $M R_{x}=M C_{X}=P_{x}\left(1-1 / \epsilon_{x}\right)$ for the $X$ industry but for the $Y$ industry we now have that $M C_{y}=P_{y}$. Thus we must replace equation (5) with

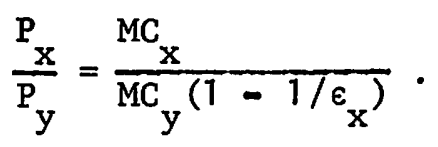

Again assuming a CES utility function, from Lemma 2 we knor that $\lim _{x \rightarrow 0} \varepsilon_{x}=\sigma$ and $\lim _{x \rightarrow \infty} \epsilon_{x}=1$. Thus we have that $\lim _{x \rightarrow 0} P_{P}=\frac{M C_{x}}{M C_{y}} \cdot \frac{1}{(1-1 / \sigma)}$, and $\lim _{x \rightarrow \infty} P_{p}=\infty$. Further since $1<\sigma<\infty, P_{p}>\frac{M C}{M C}$ for all $x$. As before, $P_{c}$ varies from $\infty$ to 0 as $x$ varies from 0 to $\infty$, so that the existence of equilim brium is established by Theorem 1 .

A difference which exists between the present case and the situation in which all industries are monopolies is that while, in Figure 3, we were able to describe a point $S$ at which $P_{p}=\frac{M C}{M C}$ and such that at all points to the left, $P_{p}<\frac{M C_{x}}{M C_{y}}$, and at all points to the right, $P_{p}>\frac{M C_{x}}{M C_{y}}$, in our present example no such point as $S$ exists, since $P_{p}>\frac{M C}{M C}$ for all $x$. Thus in our present case it is not possible even by chance for the monopoly equilibrium to be the same as the perfectly competitive equilibrium. Observe that Figure 3 could be used to describe the situation we are discussing here. It is also clear that the results for the factor price equalization theorem and the Stolper-Samuels on Theorem apply without modification. 
The reason we have selected for special attention the case where only one industry in each country is a monopoly is that this situation may have some practical significance and some attention has been given to a case which is very similar to this one, at least insofar as the implications are concerned. In the development 1iterature there has been a considerable amount of discussion about the dual economy, an econony which is dichotomized into an industrial sector and an agricultural sector. If we assume that the industrial sector tends towards monopoly, and if the agricultural sector is characterized by perfect competition, then our model may give some indication of how we would expect trade to affect this economy, or alternatively, of what kind of commercial policy the country should pursue. If this economy has a comparative advantage in the production of agricultural products, then with trade it could well find itself in the position of country $\mathrm{H}$ of Figure 3. Trade would result in a reduction of welfare and would not be the boon to development that is often expected. Indeed in this case a completely prohibitive tariff would be preferable to free trade.

Hagen ${ }^{16}$ has discussed a situation in which the economic consequences are somewhat similar to those described here. He also has a model in which the rate of transformation in production differs from the ratio of commodity prices. In his model, however, this difference is due to a distortion in the factor market which allows wages to be higher in one sector than in the other. 17 His model has been criticized for not providing

${ }^{16}$ E. Hagen, "On Economic Justification of Protectionism," Quarterly Journa1 of Economics, IXXII (November, 1958).

17 It should also be observed that in his model, due to the distortion, production is not efficient, i.e., the economy is not operating on the efficiency locus. 
an adequate mechanism to explain this wage difference, and it has been suggested that the imposition of his dynamic assumption on a static model is not appropriate. 18 The model we have described presents basically the same economic situation but is not open to these criticisms.

VI _ Summary and Conclusions

The objective of this paper has been to investigate the question of hoN, within the context of the traditional twomgood, two-factor, twocountry model, the introduction of monopoly would affect some of the traditional trade propositions. We first observed that, because the monopolist must have information about demand before a decision on price and quantity can be made, the demand and "supply" sides of the market are not independent so that the first task was to show that an equilibrium would, in fact, exist. This was rigorously done for the case where the common utility function was CES, and it was then shown that the theorem would hold under much less restrictive conditions.

The gains from trade were then considered and it was shown that in autarky the monopoly position would, in general, be inferior to the perfectly competitive equilibrium. In the case where the rest of the world was perfectly competitive, trade would thus result in larger gains than in the traditional analysis, for besides the usual gain due to specialization there will be a gain due to the elimination of domestic monopoly. In the case where there is monopoly in both countries, it was found that while one country would be expected to gain from trade, relative to both the

18 For example, see Jagdish Bhagwati and V. K. Ramaswami, "Domestic Distortions, Tariffs, and the Theory of Optimum Subsidy," Journal of Political Economy, IXXI (February, 1963). 
autarky position and to the free trade perfectly competitive position, the other country could actually be made worse off with trade in the sense that consumption coild take place in the interior of the production set. The losing country will be the one which has a comparative advantage in the good having the higher price elasticity of demand. It was even found to be possible for the world to be worse-off with trade. These situations clearly represent cases in which, for one of the countries at least, a prohibitive tariff would be justified.

The factor price equalization theorem and the Stolper-Samuels on Theorem were then examined under the assumption of monopoly, and it was found that if the same demand conditions were assumed for both countries, relative factor returns could be shown to be equal under the usual assumptions. The Stolper-Samuelson Theorem cannot be proved in the monopoly mole1, horever, due to the fact that real factor returns are no longer equal to the value of the marginal product.

The case where only one industry of each country (the sane industry) was a monopoly was examined and it was shorn that the same argument proved the existence and uniqueness of equilibrium. It was argued that this case could be relevant for underdeveloped countries which have a perfectly competitive agricultural sector and a monopolistic manufacturing sector. If comparative advantage is in the agricultural sector then the presumption is that the country will be made worse-off with trade. 


\section{Appendix A}

Consider a utility function with a constant elasticity of substitution, $\sigma$, where $\sigma=1 /(1+\beta), \beta>-1$, and $\beta \neq 0$. If there are two goods in the economy, $\mathrm{X}$ and $\mathrm{Y}$, the utility function can be represented as

(A1) $\quad U=\left(a X^{-\beta}+b Y^{-\beta}\right)^{-1 / \beta}$

Given the constraint that $M=P_{x} X+P_{y} Y$ we form the Lagrangian function (A2) $\quad \mathrm{V}=\left(a \mathrm{X}^{-\beta}+\mathrm{bY}^{-\beta}\right)^{-1 / \beta}+\lambda\left(\mathrm{M}-\mathrm{P}_{\mathrm{x}} \mathrm{X}-\mathrm{P}_{\mathrm{y}} \mathrm{Y}\right)$.

Maximizing, we obtain

(A3) $\frac{\partial V}{\partial x}=-\frac{1}{\beta}\left(a x^{-\beta}+b y^{-\beta}\right)^{-(\beta+1) / \beta}\left(-a \beta X^{-\beta-1}\right)-P_{x} \lambda=0$,

(A4) $\frac{\partial V}{\partial Y}=-\frac{1}{\beta}\left(a X^{-\beta}+b Y^{-\beta}\right)^{-(\beta+1) / \beta}\left(-a b \beta Y^{-\beta-1}\right)-P_{y} \lambda=0$,

(A5) $\frac{\partial V}{\partial \lambda}=M-P_{x} X-P_{y} Y=0$.

From (A3) and (A4), we obtain

$$
\begin{aligned}
& a X^{-\beta-1}\left(a x^{-\beta}+b y^{-\beta}\right)^{-(\beta+1) / \beta}=P_{x} \lambda, \\
& b Y^{-\beta-1}\left(a X^{-\beta}+b Y^{-\beta}\right)^{-(\beta+1) / \beta}=P_{y} \lambda .
\end{aligned}
$$


Dividing, using (A5), and solving for $Y$, we have:

$$
Y=\frac{(a / b)^{-1 /(\beta+1)}\left(P_{y}\right)^{-1 /(\beta+1)}\left(P_{x}\right)^{-\beta /(\beta+1)} M}{(a / b)^{-1 /(\beta+1)} \frac{M}{\left(P_{x}\right)^{-\beta /(\beta+1)}\left(P_{y}\right)^{\beta /(\beta+1)}+1}},
$$

or

$$
\begin{aligned}
Y= & \frac{M}{P_{y}+(a / b)^{1 /(\beta+1)}\left(P_{y}\right)^{1 /(\beta+1)}\left(P_{x}\right)^{\beta /(\beta+1)}}= \\
& \frac{P_{y}\left[1+(a / b)^{1 /(\beta+1)}\right.}{\left.\left(P_{y} / P_{x}\right)^{-\beta /(\beta+1)}\right]} .
\end{aligned}
$$

The demand function for $\mathrm{X}$, which can be derived in an identical manner is:

$$
X=\frac{M}{P_{x}\left[1+(b / a)^{1 /(\beta+1)}\left(P_{x} / P_{y}\right)^{-\beta /(\beta+1)}\right]}
$$

From these demand functions the own price elasticities, $\epsilon_{\mathrm{x}}$ and $\epsilon_{\mathrm{y}}$, can be derived as follors:

$$
\begin{aligned}
& \frac{\partial Y}{\partial P_{y}}=\frac{-M\left[1+1 /(\beta+1)(a / b)^{1 /(\beta+1)}\left(P_{y}\right)^{-\beta /(\beta+1)}\left(P_{x}\right)^{\beta /(\beta+1)}\right]}{\left[P_{y}+(a / b)^{1 /(\beta+1)}\right.} \frac{\left.P_{y}\right)^{1 /(\beta+1)}}{\left.\left(P_{x}\right)^{\beta /(\beta+1) ~}\right]^{2}}- \\
& -\varepsilon_{y} \equiv \frac{\partial Y P_{y}}{\partial P_{y}}=-\frac{P_{y}\left[1+1 /(\beta+1)(a / b)^{1 /(\beta+1)}\left(P_{y}\right)^{-\beta /(\beta+1)}\left(P_{x}\right)^{\beta /(\beta+1)}\right]}{P_{y}+(a / b)^{1 /(\beta+1)}\left(P_{y}\right)^{1 /(\beta+1)}\left(P_{x}\right)^{\beta /(\beta+1)}}
\end{aligned}
$$




$$
\varepsilon_{y}=\frac{1+(a / b)^{1 /(\beta+1)}\left(P_{y} / P_{x}\right)^{-\beta /(\beta+1)} 1 /(\beta+1)}{1+(a / b)^{1 /(\beta+1)}\left(P_{y} / P_{x}\right)^{-\beta /(\beta+1)}}
$$

Similarly,

$$
\epsilon_{\mathrm{x}}=\frac{1+(\mathrm{b} / \mathrm{a})^{1 /(\beta+1)}\left(\mathrm{P}_{\mathrm{x}} / \mathrm{P}_{\mathrm{y}}\right)^{-\beta /(\beta+1)} 1 /(\beta+1)}{1+(\mathrm{b} / \mathrm{a})^{1 /(\beta+1)}\left(\mathrm{P}_{\mathrm{x}} / \mathrm{P}_{\mathrm{y}}\right)^{-\beta /(\beta+1)}}
$$

Observe that in the derivation we have assumed that money income, $M$, is constant at al1 points on the transformation surface. This procedure is legitimate since for any price ratio nominal prices can always be adjusted to keep income constant. The elasticities will be unaffected since they are functions only of price ratios. 